\title{
Emissions Reduction of Regulated and Unregulated Hydrocarbon, Gases in Gasoline Bi-mode SI/HCCI Engine by TWC Converter
}

\section{Hasan $\mathrm{AO}^{1 *}$ and Abu-jrai $\mathrm{A}^{2}$}

${ }^{1}$ Department of Mechanical Engineering, Al-Hussein Bin Talal University, Maan, P.O. Box-20, Jordan

${ }^{2}$ Department of Environmental Engineering, Al-Hussein Bin Talal University, Maan, P.O. Box-20, Jordan

\begin{abstract}
A specific case of $\mathrm{HCCl}$ is gasoline fuelled $\mathrm{HCCl}$. It is attractive due to the simplicity of implementing such a technology into existing $\mathrm{SI}$ engines as well as the existing fuelling infrastructure. Lean and highly diluted homogeneous charge compression ignition $\mathrm{HCCl}$ engines offer great potential in improving vehicle fuel economy and contribute in reducing $\mathrm{CO}_{2}$ emissions. Gasoline is a complicated mixture of many different hydrocarbons which results in rather poor auto-ignition properties. Hydrocarbons and $\mathrm{CO}$ emissions from $\mathrm{HCCl}$ engines can be higher than those from spark ignition $(\mathrm{SI})$ engines, especially at low engine load when the EGR rate or the residual gas required to control NOx emission are elevated. Toxic chemicals emitted by SI engines, Carbonyl compounds and poly aromatic hydrocarbons $\mathrm{PAH}$ generated by $\mathrm{V} 6(\mathrm{SI} / \mathrm{HCCl})$ gasoline engine especially in $\mathrm{HCCl}$ mode. A qualitative and quantitative analysis of hydrocarbon compounds, alkenes. Alkanes, aromatics and aldehydes was analysed before and after catalyst, alkanes, alkenes and aromatic were conducted using Gas Chromatography-Mass Spectrometry (GC-MS) apparatuses. Aldehydes were conducted using High Performance liquid chromatography (HPLC) on reversed phase. HPLC system, although, bi-functional after treatment, the device will be required to control the regulated and unregulated hydrocarbon, $\mathrm{CO}$, and NOx emissions under lean and stoichiometric (oxygen free) engine operating conditions. This paper describes studies on the regulated and unregulated hydrocarbons, NOx, and $\mathrm{CO}$ emissions coming out of $\mathrm{HCC} / \mathrm{SI}$ gasoline engine. Comparative study of catalyst performance will be analysed under $\mathrm{HCCl}$ stoichiometric and $\mathrm{SI}$ operation under different engine loads, analysis indicate that, the $\mathrm{HC}$ and $\mathrm{CO}$ emissions reduction over the prototype catalyst was in the range of $90-95 \%$ while the maximum $\mathrm{NO}_{\mathrm{x}}$ emissions reduction under lean engine operating conditions was in the range of $35-55 \%$. The catalytic converter showed an excellent efficiency of eliminating unregulated hydrocarbons (alkenes, alkanes, and aromatics) and aldehydes compounds; achieved reduction efficiency was up to $92 \%$.
\end{abstract}

Keywords: Emissions; Combustion; IC engines; Catalysts; HCCI

\section{Introduction}

Homogeneous Charge Compression Ignition (HCCI) engine is an alternative piston-engine combustion process which can deliver high engine efficiency comparable with those of compression ignition (CI) engines. It has been proposed that the engine technology employing HCCI will have dual mode combustion systems, where SI or CI combustion is in use together with HCCI. One of the future directions for HCCI engine development is to widen the operating range i.e. load/ speed map [1-6]. Even if HCCI operation at high loads is obtained, the NOx reduction benefit is small compared with conventional SI engine with (TWC). Meanwhile, the fuel consumption advantage of gasoline HCCI over SI combustion is reduced at high load due to the reduced level of throttling. For high-load operation, it may require to again switch to traditional SI or CI operation. In HCCI engines the ignition timing is subject to chemical kinetics of the reactants and dependent on the fuel [7-9].

Hydrocarbon and carbon monoxide levels of HCCI engines vary between experimental conditions (e.g. engine technology and combustion modes. Though they are found to be similar or higher than those of SI engines and both $\mathrm{CO}$ and $\mathrm{HC}$ emissions are increase at light loads. Although, TWC technology has been perfected over the years for use in SI stoichiometric combustion engines, under HCCI operation or lean operation those catalysts are not effective in reducing NOx emissions. In addition switching engine operation to lean, stoichiometric or even rich is making the application of conventional oxidation catalysts challenging especially at low exhaust temperatures associated with HCCI engines [10-12]. Total hydrocarbon covered a wide range of unregulated compounds such as alkynes; alkenes; alkanes; and aromatics. Alkanes (paraffins) molecules contain single hydrogen- carbon bonds (e.g. ethane) and are referred as 'saturated'. Alkene (olefins) molecules contain double bonds (e.g. ethylene) 'unsaturated', and alkynes (i.e., acetylene), triple bonds unstable and reactive. Aromatic molecules typically display enhanced chemical stability (e.g. benzene, toluene) are building blocks for Poly (cyclic)-Aromatic Hydrocarbons (PAH) and are molecules containing two or more simple aromatic rings. Most of hydrocarbons in fuel are burnet completely during the combustion process. Small amounts of HCs, however, gets partial combustion, this produces different lower molecular HCs (in range of C1-C5) and some oxidized compounds such as aldehydes [13]. Aromatics in a fuel may survive the combustion process and could be more emitted through the exhaust as unburned HCs. At poor combustion, and engine misfiring, large amounts of hydrocarbons are emitted from the combustion chamber. The mass distribution of these species in the exhaust is a function of the engine design, fuel composition, and the engine operation conditions. Another cause of excessive $\mathrm{HC}$ emissions is related to combustion chamber deposits. Because these carbon deposits are porous, $\mathrm{HC}$ is forced into these pores as the air/fuel mixture is compressed. When combustion takes place,

*Corresponding author: Hasan AO, Department of Mechanical Engineering, AlHussein Bin Talal University, Maan, PO Box-20, Jordan, Tel: 00962777793888 ; E-mail: Ahmad_almaany@yahoo.com

Received May 13, 2016; Accepted June 27, 2016; Published June 30, 2016

Citation: Hasan AO, Abu-jrai A (2016) Emissions Reduction of Regulated and Unregulated Hydrocarbon, Gases in Gasoline Bi-mode SI/HCCl Engine by TWC Converter. J Appl Mech Eng 5: 224. doi:10.4172/2168-873.1000224

Copyright: (c) 2016 Hasan AO, et al. This is an open-access article distributed under the terms of the Creative Commons Attribution License, which permits unrestricted use, distribution, and reproduction in any medium, provided the original author and source are credited. 
this fuel does not burn; however, as the piston begins its exhaust stroke, these HCs are released into the exhaust stream [14-17].

Wall quenching occurs as the combustion flame front burns up to the relatively cool walls of the combustion chamber. This cooling extinguishes the flame before all of the fuel is fully burned, leaving a small amount of $\mathrm{HC}$ to be pushed out the exhaust valve. This is the major source of $\mathrm{HC}$ emissions from four-stroke engines.

This manuscripts presents study on a new catalytic converter design, aiming to control regulated and unregulated hydrocarbons, $\mathrm{CO}$ and NOx emissions under stoichiometric, HCCI/SI engine operation and different engine loads. The experiments were conducted on a V6 gasoline engine equipped with the prototype catalyst at the one bank. The effects of engine loads and modes were analysed.

\section{Experimental Procedure}

Engine - The experimental work was performed on a V6 HCCI/ SI mode gasoline direct injection (GDI) engine image 1 . The engine intake and exhaust camshafts were built with variable cam timing (VCT) and cam profile switching (CPS) system. Fuel direct injection pulse width is adjusted by the engine management system to maintain the required value of $\lambda$. The engine was coupled to an eddy-current dynamometer for speed and load control, twelve thermocouples type $\mathrm{K}$ were installed to monitor the exhaust and inlet temperature. Intake and exhaust cam timing for minimum residuals were chosen to start the engine with spark ignition combustion. When engine block achieved steady condition of temp level in SI mode, the HCCI combustion mode was started.

Catalyst - The prototype three zones monolith catalyst, with optimized order of the zones, was connected to the actual engine exhaust manifold. The ceramic monolith dimensions and hence volume were the same as the production TWC, the engine was originally equipped. The first catalyst zone contains base metal catalyst and was designed to control part of the exhaust hydrocarbons and CO. The second zone again contains base metal catalyst was designed to reduce $\mathrm{NOx}$ with $\mathrm{HC}$ under lean engine operation while the third zone which contain precious metals (e.g. Pt) was designed to reduce $\mathrm{HC}, \mathrm{CO}$ and $\mathrm{NOx}$ under lean and stoichiometric engine conditions.

Emissions analysis - Horiba MEXA 7100 DEGR (HC, CO, NOx, and $\mathrm{CO}_{2}$ ) was connected to measure the exhaust emissions upstream and downstream the catalyst.

Hydrocarbon speciation of C5-C11 compounds was carried out using an on-line GC-MS. An 8000 series GC equipped with direct injector was connected to a Fisons MD 800 mass spectrometer, used as a detector. The gas samples were introduced via a heated line into a six port Valco valve outfitted with a $0.1 \mathrm{ml}$ sample loop. The gas sampling apparatus was kept at a constant temperature of $200^{\circ} \mathrm{C}$. A 30 meter long x $0.53 \mathrm{~mm}$ i.d. DB- 1 capillary column with a $3 \mu \mathrm{m}$ film thickness was used, this type of column allows for separation of both the polar and non-polar compounds.

Carbonyls: The samples were carried out by passing the engine exhaust gas with flow rate of $1.0 \mathrm{~L} / \mathrm{min}$ in to $25 \mathrm{ml}$ midget impinger and the exhaust gas bubbled inside the DNPH solution reagent for 20 minutes, during the test the sample must be surrounding by bath of ice to prevent any vaporising of the compound species during the sampling. When the exhaust gas bubbles in the DNPH solution the carbonyl compounds react with the reagent to produce $\mathrm{DNPH}$ - carbonyl derivatives. Each sample was kept in the fridge below $4^{\circ} \mathrm{C}$ until HPLC analysis takes place. Carbonyl species analysis, were performed by
High Performance liquid chromatography (HPLC) on reversed phase. HPLC system was used Dionex Acclaim 120, separation of the sample components was achieved on a $250 \mathrm{~mm}$ x $4.6 \mathrm{~mm}$ ID. Column backed with $5 \mu \mathrm{m} \mathrm{C18} \mathrm{Acclaim} \mathrm{120.} \mathrm{UV} \mathrm{detector} \mathrm{was} \mathrm{used} \mathrm{and} \mathrm{the} \mathrm{wavelength}$ was set to $365 \mathrm{~nm}$. a mobile phase solvent gradient of acetonitrile and deionised water was $(10: 90 \mathrm{v} / \mathrm{v})$ used as an eluent, the flow rate of the eluent was adjusted to $1.0 \mathrm{ml} / \mathrm{min}$ and the mixing ratio was changed linearly to reach $75: 25 \mathrm{v} / \mathrm{v}$ acetonitrile to deionised water at $60 \mathrm{~min}$, and then kept constant to the end of the run, the analysing time for the a single measurement was 70 minutes (Figure 1).

\section{Results and Discussion}

Hydrocarbon and CO emissions are influenced by the in-cylinder conditions (i.e., temperature) and the homogeneity of the fuel with air. Increasing engine load from 3-4 bar improves $\mathrm{HC}$ and $\mathrm{CO}$ oxidation which leads to significant reduction of $\mathrm{HC}$ and $\mathrm{CO}$ emissions, on the other hand the opposite trend seen in the case of NOx emission when the engine load was increased. In case of $\mathrm{HC}$ this was presumably because crevice loading of $\mathrm{HC}$ with lower load has a bigger effect on HC emissions than that with a higher load. The burned gas temperature at low load seems to be too low for the crevice hydrocarbons to be oxidized during the expansion stroke, comparing to the higher gas temperature. The lower gas temperature is not favourable for $\mathrm{HC}$ oxidation in the exhaust ports. Furthermore, the low combustion gas temperature presented at low load can result in incompletion of the combustion process and cause higher HC [18]. Similarly when load is decreased CO emissions increased. This rapid increase resulted from the quenching of the $\mathrm{CO}$ oxidation process in the lower load as the gas temperature dropped. Dec [19] predicted that for low loads, incomplete bulk-gas reactions should play a significant and perhaps dominant role in $\mathrm{CO}$ emissions and this contributes to $\mathrm{HC}$ emissions. NOx reduction has been a result of lower combustion temperature in the homogeneous combustion associated with dilution and an increased heat capacity as an exhaust gas is used to dilute the cylinder mixture. Under most engine operation the prototype catalyst covered a wide range of engine conditions, HCCI stoichiometric and SI mode, this led to approval consistency of $\mathrm{HC}$ and $\mathrm{CO}$ conversions above $90 \%$ over the catalyst independently from in-cylinder conditions (Figure 2).

Figure 3 shows that the HCCI combustion with residual gas trapping produced much less $\mathrm{CO}$ emissions than SI engine mode which was confirmed by other studies using the residual gas trapping method [20]. The reduction in CO emission is likely caused by the recycling of burned gases and their subsequent conversion in to $\mathrm{CO}_{2}$ in the

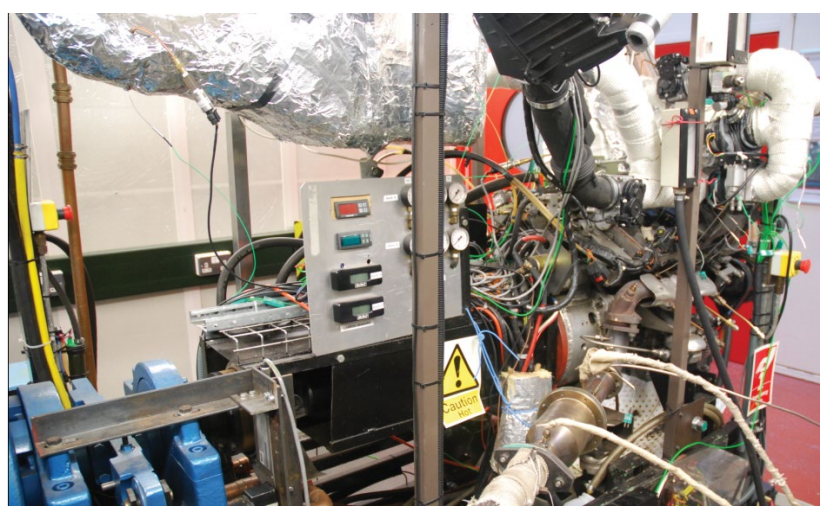

Figure 1: Schematic diagram of a $\mathrm{V} 6$ engine system and the prototype catalytic converter. 
next cycle. It should be noted that HCCI combustion in the 4-stroke gasoline engine had been always associated with higher $\mathrm{CO}$ emissions than the SI combustion until the residual gas trapping method was employed [21].

Minimal catalytic conversion of $\mathrm{NOx}$ emissions up to $55 \%$ efficiency occurred at HCCI mode this is correlated with $\mathrm{CO}$ and $\mathrm{HC}$ emissions. When $\mathrm{CO}$ and $\mathrm{HC}$ emissions are relatively low (and exhaust temperature is low) the $\mathrm{CO}$ oxidation deteriorates and allows higher efficiency of NOx reduction (more CO available for reduction reaction). Despite the catalyst lower NOx conversion efficiencies under HCCI mode, NOx emissions after the catalyst were kept at lower values compared to SI (Figure 4). Further discussion is in (Figures 5-7).

\section{Alkenes}

Unsaturated hydrocarbon compounds (olefins ) presented in the engine tails in a great concentration, with HCCI mode at engine load of 3 bar, alkenes showed a high concentration just over $600 \mathrm{ppm}$ and was reduced about $50 \%$ when shifting to higher load of 4 bar. Changing engine mode from HCCI to SI engine mode did not influence much the alkene concentration, the proto type convertor showed high conversion efficiency at high load 4 bar for both engine modes. Catalyst efficiency reached over $90 \%$.

\section{Alkanes}

Paraffin saturated hydrocarbons with open - chain compound has high concentration in HCCI mode with engine load of 3 bar, shifting

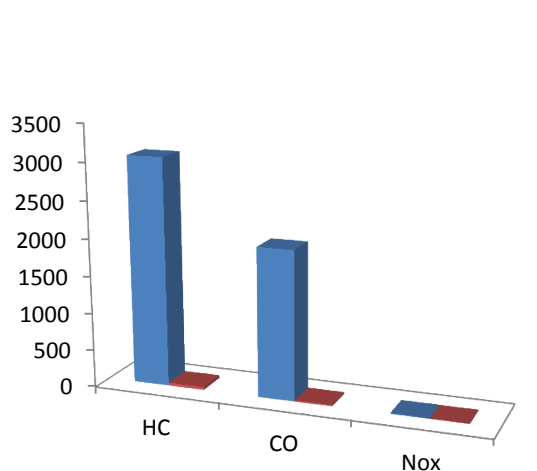

npm before catalyst

- ppm after catalyst

Figure 2: Engine out emissions before and after catalyst $\mathrm{HC}, \mathrm{CO}$, and NOx (3 bar NMEP), $\mathrm{HCCl}$, lambda 1.

- ppm before catalyst

npm after catalyst

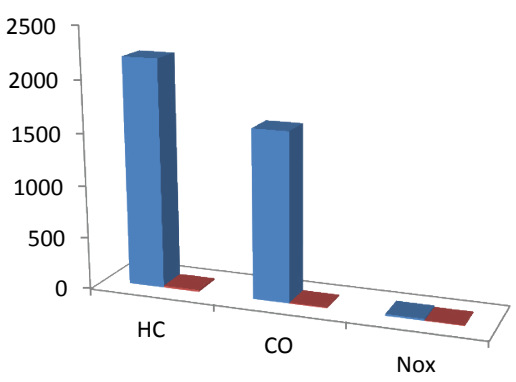

Figure 3: Engine out emissions before and after catalyst of $\mathrm{HC}, \mathrm{CO}$, and NOx (4bar NMEP), HCC, lambda 1.

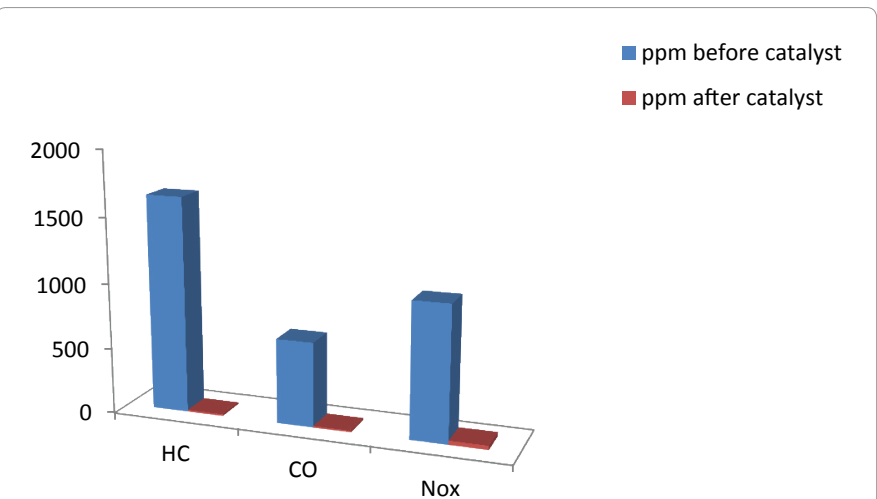

Figure 4: Engine out emissions before and after catalyst $\mathrm{HC}, \mathrm{CO}$ and $\mathrm{NOx}$, (4bar NMEP), SI, lambda 1.

- ppm before catalyst

npm after catalyst

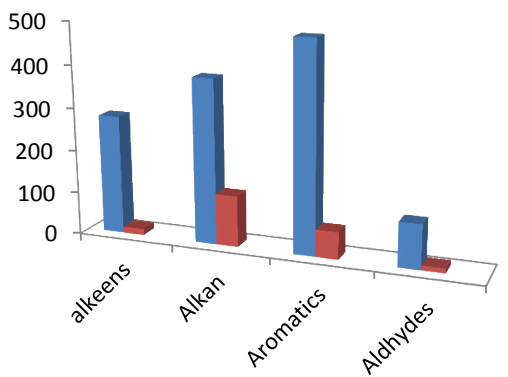

Figure 5: Engine out emissions before and after catalyst (4bar NMEP), $\mathrm{HCCl}$, lambda 1.

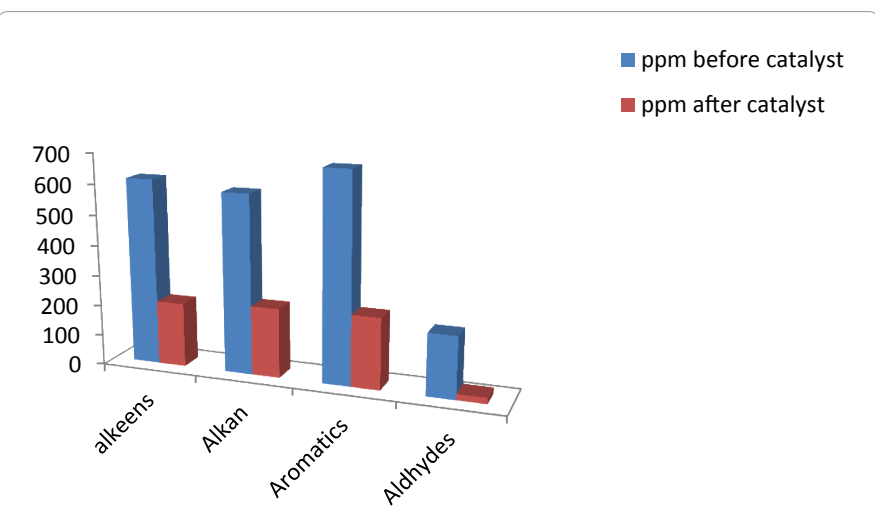

Figure 6: Engine out emissions before and after catalyst (3bar NMEP), $\mathrm{HCCl}$, lambda 1.

to higher engine load 4 bar has reduced alkane concentration down to $30 \%$, on the other hand alkanes presented with less concentration in SI engine mode with the same load, the best conversion efficiency found in SI mode, followed by HCCI mode with engine load of 3 bar.

\section{Aromatics}

The chemical compound of aromatics contain a conjugated planer ring stable ring tends to form easily, and once it is formed tends to be difficult to brake in chemical reactions, this compounds was presented in a largest concentration among other chemical compounds especially 


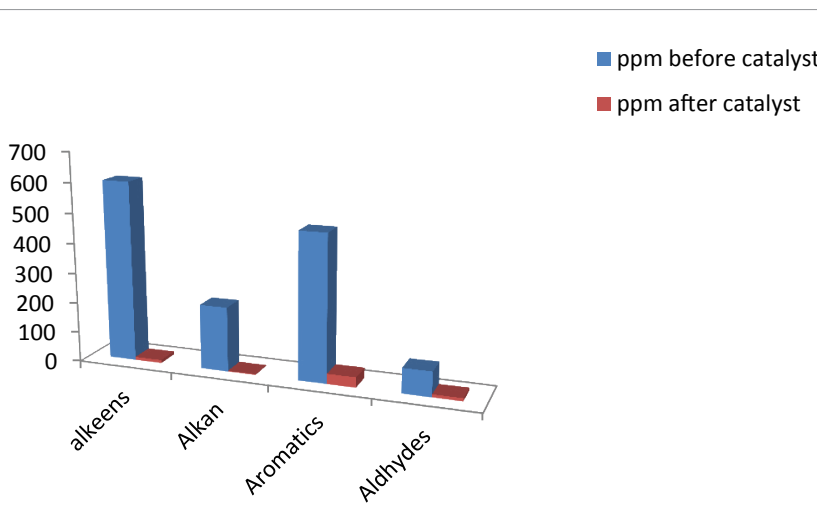

Figure 7: Engine out emissions before and after catalyst (4bar NMEP), SI, lambda 1.

in HCCI engine mode at load of 3 bar, when shifting to higher load of 4 bar concentration was reduced $20 \%$, in SI engine mode aromatics concentration were similar to HCCI mode at the same engine load of 4 bar, the best conversion efficiency presented with SI engine mode, and HCCI mode at the same engine conditions. Conversion efficiency reached $92 \%$.

\section{Aldehydes}

Aldehydes are hydrocarbons with additional embedded oxygen atoms. These $\mathrm{O}-\mathrm{H}-\mathrm{C}$ compounds are produced mainly during the combustion of fuels with high oxygen content, (e.g. aldehydes, ketones and alcohols). Aldehydes are formed from incomplete combustion in the cylinder, and by thermal decomposition in the exhaust system, the highest concentration of aldehydes presented in HCCI mode at engine load of 3 bar, and reduced about 55\% when engine shifted to higher load of 4 bar, the minimum concentration existed in SI mode at 4 bar, high conversion efficiency presented at all engine modes and different loads, it ranged from $86 \%-90 \%$.

\section{Conclusions}

(i) Engine-out emissions: Hydrocarbon, $\mathrm{CO}$ and $\mathrm{NOx}$ are influenced by engine operation and combustion mode (i.e. HCCI or $\mathrm{SI})$. $\mathrm{HC}$ and $\mathrm{CO}$ emissions were higher in HCCI mode while NOx emission is found to be more in SI. Analysis shows HC, CO in HCCI mode are heavily dependent on engine load.

(ii) Unregulated compounds: in HCCI mode, aromatic concentration were the highest followed by alkanes, alkenes and aldehydes. At lower load all compounds have increased regardless of engine conditions. Alkenes were influenced by changing engine load more than engine modes. Alkane's compound influenced more by engine mode than engine load. Aromatic compound presented with high concentration in all engine modes and operation. Aldehydes species found to be in a low concentration in all engine conditions.

(iii) Post-catalyst emissions: High consistency of $\mathrm{HC}$ and $\mathrm{CO}$ conversion was approximately $90 \%$ over the prototype catalyst independent from in-cylinder conditions which has been designed to combine the catalytic functions required to oxidise $\mathrm{CO}$ and hydrocarbons, while simultaneously reducing NOx over the expected range of exhaust-gas temperatures and stoichiometries, during operation of an engine in both HCCI and SI modes. During HCCI higher load, this catalyst shows more efficient conversion of alkenes and aldehydes up to $95 \%$, on the other hand only $70 \%$ was achieved in reducing alkanes. Catalyst was more efficient in reducing the chemical compounds in higher load than lower engine load. Excellent catalyst efficiency was achieved in SI mode, all chemical compounds were eliminated.

\section{References}

1. Lü X, Hou Y, Zuz L, Huang $Y$ (2006) Experimental study on the auto-ignition and combustion characteristics in the homogeneous charge compression ignition $(\mathrm{HCCl})$ combustion operation with ethanol/n-heptane blend fuels by port injection. Fuel 85: 2622-2631.

2. Machrafi HS, Cavadias J, Amouroux $P$ (2008) A parametric study on the emissions from an $\mathrm{HCCl}$ alternative combustion engine resulting from the autoignition of primary reference fuels. Applied Energy 85: 755-764.

3. Su H, Vikhansky A, Mosbach S, Kraft M, Bhave A, et al. (2006) A computationa study of an $\mathrm{HCCl}$ engine with direct injection during gas exchange. Combustion and Flame 147: 118-132.

4. Wang Z, Shuai SJ, WangG JX, Tian H (2006) A computational study of direct injection gasoline $\mathrm{HCCl}$ engine with secondary injection. Fuel 85: 1831-1841.

5. Ying W, Li H, Jie ZZ (2009) Longbao study of HCCl-DI combustion and emissions in a DME engine. Fuel 88: 2255-2261.

6. Zheng ZM, Yao L (2009) Charge stratification to control $\mathrm{HCCl}$ : Experiments and CFD modeling with n-heptane as fuel. Fuel 88: 354-365.

7. Abu-Jrai A, Tsolakis A, Megaritis $Y(2007)$ The influence of $\mathrm{H}_{2}$ and $\mathrm{CO}$ on diesel engine combustion characteristics, exhaust gas emissions, and after treatment selective catalytic NOx reduction. International Journal of Hydrogen Energy 32 : 3565-3571.

8. Ludykar D, Westerholm J, Almén R (1999) Cold start emissions at $+22,-7$ and $-20^{\circ} \mathrm{C}$ ambient temperatures from a three-way catalyst (TWC) car: regulated and unregulated exhaust components. The Science of the Total Environment 235: 65-69.

9. Zervas E, Montagne X, Lahaye J (2004) Influence of fuel and air/fuel equivalence ratio on the emission of hydrocarbons from a $\mathrm{SI}$ engine. 1. Experimental findings. Fuel 83: 2301-2311.

10. Sartipi S, KhodadadiY AA, Mortazavi S (2008) Pd-doped $\mathrm{LaCoO}_{3}$ regenerative catalyst for automotive emissions control. Applied Catalysis B: Environmental 83: 214-220.

11. Schlatter JC, Taylor KC (1977) Platinum and palladium addition to supported rhodium catalysts for automotive emission control. J Catalysis 49: 42-50.

12. Winkler A, Dimopoulos P, Hauert R, BachM C (2008) Aguirre catalytic activity and aging phenomena of three-way catalysts in a compressed natural gas/ gasoline powered passenger car. Applied Catalysis B: Environmental 84: 162-169.

13. Andrews GE, Ahmed FM, Li H (2007) Condensable and gaseous $\mathrm{HC}$ emissions and their speciation for a real world SI car test. SAE International.

14. Leclerc B (2008) Detailed chemical kinetic models for the low-temperature combustion of hydrocarbons with application to gasoline and diesel fuel surrogates. Progress in energy and combustion science 34: 440-495.

15. Kaiser EW, SiegI WO, Henig YI, Anderson RW, Trinker FH (1991) Effect of fuel structure on emission from a spark-ignited engine. Environ Sci and Technol 26: 1581-1586.

16. Kaiser EW, SiegI WO, Cotton DF, Anderson RW (1992) Effect of fuel structure on emission from a spark-ignited engine with naphthene and aromatic fuels. Environ Sci and Technol 26: 1581-1586.

17. Kaiser EW, Siegl WO, Cotton DF, Anderson RW (1993) Effect of fuel structure on emission from a spark-ignited engine with olefinic fuels. Environ Sci Technol 27: $1440-1447$.

18. Maurya K, Agarwal K (2008) Combustion and emission behaviour of ethano fuelled homogeneous charge compression ignition $(\mathrm{HCCl})$ engine. SAE.

19. Dec $E$ (2002) A computational study of the effects of low fuel loading and $E G R$ on heat release rates and combustion limits in $\mathrm{HCCl}$ engines. SAE.

20. Koopmans L, Denbratt L (2001) A four stroke camless engine operated in homogeneous charge compression ignition mode with a commercial gasoline. SAE.

21. Zhao $\mathrm{H}(2007) \mathrm{HCCl}$ and $\mathrm{CAl}$ engines for the automotive industry. CRC Press Cambridge England. 